\title{
FEMALE COOPER'S HAWK BREEDING IN BROWN PLUMAGE, APPARENTLY FOR FOUR YEARS
}

E. OTTO HÖHN, Department of Physiology, University of Alberta, Edmonton, Alberta. T6G 2H7

A small proportion of female Cooper's Hawks breed while still in juvenile plumage. Such birds were observed in 2 out of 36 pairs by Meng and in 2 out of 34 pairs by Reynolds and Wight. ${ }^{3}{ }^{4}$ In male Cooper's hawks this phenomenon is evidently much more unusual. Rosenfield and Wilde report an instance and wrote that they knew of only one other case. ${ }^{5}$

In these accipiters the molt into the adult plumage normally begins in the spring of their first full year and is not complete until the following fall. It seems likely that in most of the females breeding in juvenile plumage noted above development of the mature plumage was merely delayed for a few months and that they were in the adult plumage during their second breeding season.

Strong circumstantial evidence, set out below, indicates that I observed one and the same female in a brown plumage (apparently different from that of normal juveniles), which bred in the same small grove of trees in 1979, 1980 (no observations in 1981) and 1982. However since it was not artificially marked there is no absolute proof that the same individual was involved throughout.

The relevant observations are as follows: on 19 August 1979 in the poplar wood of about 6 ha, in which all subsequent observations were made, I saw a brown (judging by its size) female Cooper's Hawk. It cackled, ap- parently defiantly, from a slim tree trunk which was bent over like a hoop and so offered the hawk a nearby horizontal perch. In the trees nearby were two young Cooper's Hawks which could already fly. On a subsequent visit to this spot I noticed the empty nest in the fork of a sizeable poplar a few metres from the spot where I had seen the hawks.

On 1 July 1980 the "ga ga ga" calls and agitated flying about of a brown female enabled me to find the current nest which was only about $200 \mathrm{~m}$ from that used the year before. Two young hawks were perched in branches of the nest tree. On 26 July there were three young nearby, (and at times in the nest) and a fourth which stayed in the nest. By watching the nest from partial concealment a fairly close view of the female was obtained through $10 x$ binoculars as she perched briefly in a low branch. Her upper parts, apart from darker bars across the tail, were uniformly beige, paler than the brown of the backs of the young. I failed to record the colour of her lower parts but believe that they were merely paler than the rest and without the conspicuous spots of the normal juvenile or the bars of the adult plumage. Her eyes were bright orange red as they normally are in adults, a point which makes it unlikely that she was a yearling. The male was not seen in the wood during visits up to 19 August when two of the young were last seen there. On this and other occasions they called "ga ga ga" like the adult female and 
when apparently begging for food uttered a plaintive "pee aa" usually repeated 2-3 times. During July the pectoral girdles of 2 young Ruffed Grouse and a nearly intact Red-backed Vole were found on the ground beneath the nest.

In 1981 I was out of the country for all of July and part of August. No Cooper's Hawks were seen in the wood during visits there before and after this period.

On 1 May 1982 I saw a "brown" adult fly into the nest which had been used in 1980. Apparently it noticed me almost immediately for it flew to a tree some $20 \mathrm{~m}$ away, cackled and twice more flew to another perch and finally out of sight. No visits to the nest were made for 2 weeks lest the birds desert. On 14 May the nest looked as if some twigs had been added to it in the interval. Cackling calls, softer than the female's, led me to a nearby sedgegrown clearing where I found the male perched on an arch-like pole. It was possible to observe this hawk without causing it to fly away.

On 15 May I flushed this bird from the edge of the clearing. A dead poplar, broken off three feet from the ground but still connected to the longer upper part, supported in a horizontal position by other trees, evidently served as the hawk's plucking log. Feathers of a solitary sandpiper and of two unidentifiable robin-sized birds, apparently of different species, were found there as well as some vole or mouse hair. In the course of repeated visits up to 7 August, the last date when remains of prey were found by the log, the following items were identified: 4 Red-winged Blackbirds, 2 Robins, a Sora, a Mountain Bluebird, a Yellow Warbler, an adult female Green- or Blue-winged Teal, some Snowshoe Hare fur. The Solitary Sandpiper, Sora, teal, bluebird and Yellow Warbler are not listed by
Meng among the food items of nesting Cooper's Hawks in New York State and Pennsylvania. ${ }^{2}$ No doubt local availability accounts for differences in the two lists, but a full-grown teal is notably large prey for this hawk.

When examined on 29 May the nest held four eggs. The brown female was flushed from the nest several times before and after this date. On 23 June there were young judged to be about 3 days old and a cracked egg in the nest. Pieces of the shell of one egg were found about $5 \mathrm{~m}$ from the base of the nest tree. Brown and Amadon state that the female carries the egg shells 50 yards or farther from the nest. ${ }^{1}$ In early June a few primaries and a tail feather, evidently moulted by the female, were found between the nest tree and the plucking log.

On 2 August two fully feathered young, apparently all that had survived, were perched near the nest but flew off cackling at my approach. Only on this occasion were remains of prey, of a sparrow-sized bird and feathers of a blackbird, found below the nest. Next day the two young were seen near the plucking log below which lay the plucked trunk of a robin.

The usual call of the adult female was the cackle already described but on a few occasions after leaving the nest or when about to return to it she uttered softer short "keek" or sharper "pfeet" calls.

On 29 April 1983 I had a glimpse of a Cooper's Hawk flying out of the nest which had been used the year before. The site was left undisturbed until 13 May when I found the nest much enlarged, (with the addition of a branch with green leaves) and occupied by a Red-tailed Hawk which, with its partner, eventually raised young there. On a few occasions thereafter an adult Cooper's Hawk was seen on hunting 
flights in the general area but I was unable to find a nest.

1 BROWN, L. and D. AMADON. 1968 Eagles, hawks and falcons of the world. McGraw-Hill, New York. 945 pp.

2 MENG, H. 1959. Food habits of nesting Cooper's Hawks and Goshawks in New York State and Pennsylvania. Wilson Bull. 71:169-174.
3 MENG, H. 1951. The Cooper's Hawk. Ph.D. Thesis. Cornell University, Ithaca, N.Y.

4 REYNOLDS, R.T. and H.M. WIGHT 1978. Distribution density and productivity of accipiter hawks breeding in Oregon. Wilson Bull. 90:182-196.

5 ROSENFIELD, R. N. and J. WILDE 1982. Male Cooper's Hawk breeds in juvenile plumage. Wilson Bull. 94:213.

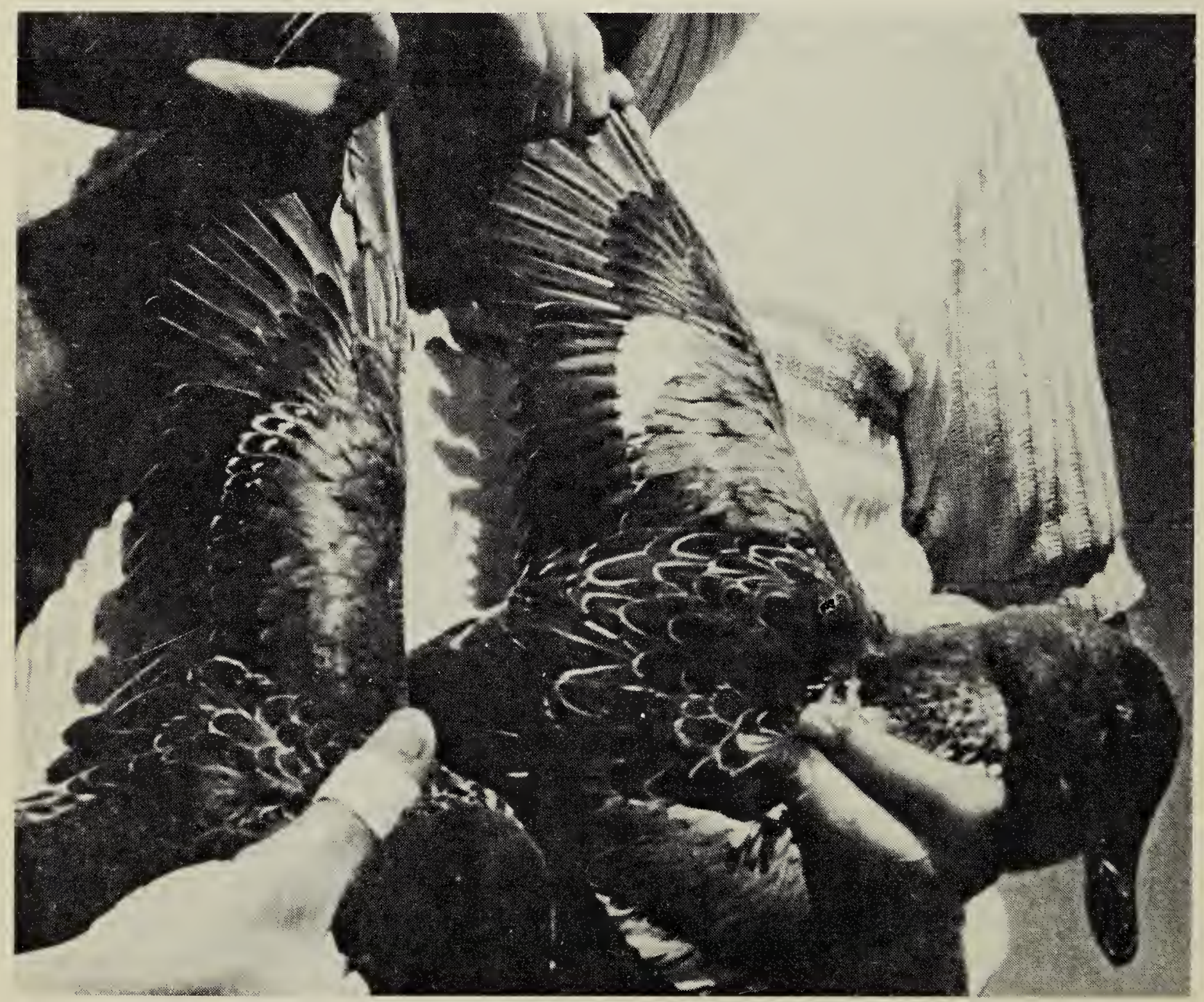

